Proceedings of the 50th Hawaii International Conference on System Sciences | 2017

\title{
Financial Decision Support System for Wind Energy - Analysis of Mexican Projects and a Support Scheme Concept
}

\author{
André Koukal \\ Leibniz University Hannover \\ koukal@iwi.uni-hannover.de
}

\author{
Jan-Hendrik Piel \\ Leibniz University Hannover \\ piel@iwi.uni-hannover.de
}

\begin{abstract}
Energy consumption is constantly on the increase all over the world. Especially fast-growing economies in emerging countries contribute to this increase. Governments need to promote the expansion of renewable energies in these countries by providing adequate general conditions and suitable support schemes. We provide decision support for the assessment of wind energy projects and their financial conditions. Following design science research (DSR) principles, a discounted cash flow (DCF) model in combination with a Monte Carlo simulation (MCS) to consider project risks was created. On this basis, a decision support system (DSS) was implemented in MATLAB. The applicability of the DSS is evaluated in the course of an analysis of onshore wind projects in Mexico. Based on the analysis' results, a concept of a support scheme is designed to promote an expansion of onshore wind energy across Mexico.
\end{abstract}

\section{Introduction}

The worldwide demand for energy has been increasing in the last few decades and will continue to do so in the future, with major differences regarding the individual countries. While the energy consumption in countries of the OECD and non-OECD countries was roughly equal in 2007 , the energy consumption will increase by 14 percent in OECD countries compared to 84 percent in non-OECD countries by 2035 [1]. As the global climate change process is influenced by greenhouse gas emissions and thus by the generation of electricity, to limit negative ecological effects, an intensive expansion of renewable energies seems not only necessary, but mandatory.

Wind energy is expected to make the largest contribution to this expansion by increasing its share on the worldwide energy production from 2 percent in 2009 to 8 percent in 2035 [2]. The biggest potential is in the developing and emerging countries e.g. in Central and South America as there has been no intensive use so far [2]. Due to its long coastline particularly Mexico has many regions which offer average wind speeds that are otherwise rather typical for offshore locations. The estimated maximum installed capacity of onshore wind energy (OWE) in Mexico is 40,000 MW [3] of which only 3,073 MW have been used at the end of 2015 [4]. Almost all wind farms are located in Oaxaca, the region with the strongest winds. To promote the further expansion of wind energy also outside of Oaxaca, the introduction of a support scheme which considers all Mexican regions is crucial. Sustainability and Green IS are also becoming a major topic within the IS research domain [5]. Heavy use of information technology (IT) is one factor of the increasing energy consumption and emission of greenhouse gases. However, the use of IS can also contribute to higher sustainability. Green IS enables the evaluation and optimization of processes and products to raise resource efficiency.

In existing literature little support for the assessment of onshore wind farms and their respective general financial conditions across a country to design the concept of a support scheme exist. To fill this void, this paper provides decision support for the assessment of wind projects. Based on existing research, an adjusted DCF model is formulated and extended with various risk measures, correlations between these factors and an MCS. The DCF model and MCS are integrated into the DSS "investment and risk analyses of wind energy projects" (INRIAN-WE). The following research questions are addressed:

(RQ) How can decision support be provided for investors, lenders and policy makers to access OWE projects and corresponding support schemes to stimulate investments and a further expansion?

The paper is structured as follows: first, the research background is addressed, including foundations, related work, and research design. Next, an approach to assess wind energy projects is provided. Our implemented DSS as well as the underlying model and methods are presented. Section four includes a case study about the wind energy sector in Mexico. In section five, results are discussed, and recommendations and limitations are provided. The paper ends with a conclusion and an outlook. 


\section{Research background}

The increasing interest in environmental and economic sustainability of societies also reached the IS research domain when Watson et al. [6] called for more attention to energy informatics and ecofriendliness in 2010. However, the achievements that shaped Green IS as a subfield in the IS discipline were not followed by a sufficient uptake in research [7].

\subsection{Related work}

The wind energy sector developed rapidly over the last twenty years but the focus in research has been more on technical aspects. A recent change in focus deals with the economic feasibility of wind energy projects. However, as most related publications deal with the offshore sector, only a few corresponding publications exist for the onshore sector.

Market reports from the Global Wind Energy Council (GWEC) [4], the International Energy Agency (IEA) [8] and the International Renewable Energy Agency (IRENA) [9] provide multiple findings about various project aspects and frameworks in countries all over the world.

An assessment of wind energy potential in Mexico was performed by Jaramillo and Borja [10] as well as Jaramillo et al. [11]. They focus on the wind speed distributions in certain regions. Hernández-Escobedo et al. [12] performed a similar analysis but investigated wind speeds for all Mexican regions. However, none of the studies provides financial insights.

Blanco [13] compares the operating costs and the cost structures of onshore and offshore wind farms. Forecasts of future energy prices are presented. Her findings provide a general economic overview, but do not enable a detailed analysis of a single wind farm.

Other publications address the calculation of relevant key figures like the net present value (NPV) or the internal rate of return (IRR) for OWE investments by using deterministic models. Such a model is provided by De Oliveira and Fernandes [14]. Although they do not analyze a specific case study, the discounted payback period and the levelized required revenues are added to the previous key figures. Other examples are the models provided by Peña et al. [15] who focus on the probability of existing wind farms in Portugal and Colmenar-Santos et al. [16] who assess the economic feasibility of repowering in the wind energy sector of Spain.

All studies with deterministic models lack in an adequate consideration of risks. One possibility to address this issue is the implementation of probabilistic analyses by performing a Monte Carlo simulation.
The research of Kitzing and Weber [17] includes an entire risk-adjusted cost-benefit analysis of wind energy projects based on an MCS. They utilize the MCS to enable value-at-risk (VAR) analyses of important key figures. A similar approach is utilized by Khindanova [18] who implemented an MCS to investigate the impact of electricity price and cost uncertainties on the NPV of wind energy investments.

Koukal and Breitner [19] constructed a DCF model to determine the APV and additional key figures like the debt service cover ratio (DSCR) for offshore wind projects in Brazil. Their research is based on the approach of Madlener et al. [20]. They consider project risks by assigning probability distributions for each risky parameter and also apply an MCS. They embed their constructed model into an DSS.

Our literature research indicates that no publication addresses the financial assessment of OWE projects in many different regions in Mexico. Additionally, there is no discussion about a suitable concept for an OWE support scheme in Mexico. Although several mathematical models are implemented to evaluate individual projects, in most cases they neither take risks and corresponding correlations into account nor implement a system with visualization options to provide decision support.

Although the approach of [19] and [20] focusses on the offshore sector and do not consider correlations between risk factors, their DCF models serve as a foundation to formulate a more complex model that enables us to analyze projects.

\subsection{Research design}

Our research was conducted using DSR principles in order to address relevance and enhance rigor of the research process and results. The design-oriented research process was advised by Offermann et al. [21] and, in particular, Peffers et al. [22]. Additionally, we used key recommendations provided by Hevner et al. $[23,24]$. The actual research design is classified as a problem-centered approach (see Figure 1).

The lack of studies on the assessment of specific wind energy projects and the design of a support scheme in Mexico against the background of a constantly increasing energy demand but very high wind energy potential triggered the development of our DSS. We initiated our research process by identifying the above-mentioned problem (I). To ensure methodological rigor, foundational information must be assembled from the academic body of literature [23]. We conducted a comprehensive literature review within the fields of energy informatics and the general finance and IS research domain. Additionally, we conducted a targeted review within the DSR domain. 


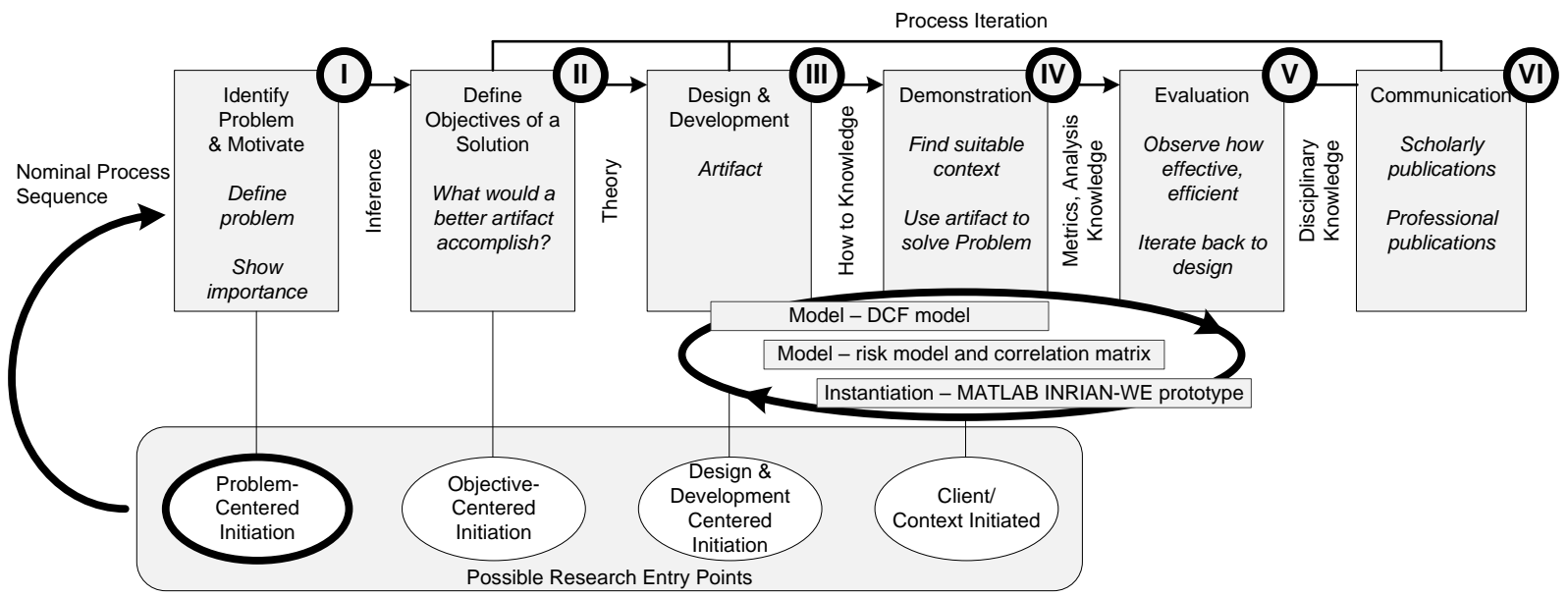

Figure 1: Research design according to the DSR methodology process [22]

According to the research question, we mainly focused on the design, demonstration, and evaluation of artifacts that can provide a basis to assess location based general and financial conditions for wind energy projects in a specific country (II). With regard to this objective, the practical and scientific input was used to design and evaluate artifacts in a loop of iterations in the design cycle according to [24]. After refining the problem domain and defining specific requirements, the first research artifact was designed (III) in previous research [19]: a basic DCF model. It was limited to central aspects of wind energy projects with its investment and operating cash flow, the consideration of support schemes and the project value calculation.

For a further development and a more detailed elaboration we used an iterative approach to generate and refine artifacts cyclically according to guideline six, "design as a search process", by [24] (see Figure 1). We examined additional risk factors and enhanced our initial model by implementing a more complex risk model that enables the application of an MCS.

A classification into constructs, models, methods, and instantiations as the result of design-oriented research is provided by [24]. In addition to the constructed formal models, an instantiation was created by the implementation of our INRIAN-WE prototype in MATLAB. The MATLAB implementation is more suitable regarding performance, flexibility, risk correlations than our previous spreadsheet implementation [19]. According to the classification of research methodologies by Palvia et al. [25], a case study in the form of project value and debt coverage calculations for OWE projects at different locations in Mexico in combination with the design of support scheme components was performed to demonstrate (IV) and evaluate (V) the capabilities of the DSS. Finally, we worked toward publishing our research results (VI).

\section{Assessing wind energy projects}

The objective of our approach is to assess the economic profitability and financial feasibility of OWE projects under prevailing general financial conditions. It subsequently allows us to check if these conditions are sufficient to promote the expansion of the wind energy sector or else to introduce or improve the underlying support scheme.

\subsection{Discounted cash flow model}

The basis for the assessment of a project is a DCF model. Our model is used to calculate an OWE project's free cash flow (FCF) over the entire project life. It represents the after-tax cash flow available to the project's investors and must be initially used to cover the debt service. Figure 2 shows the sets, parameters, and key equations of our cash flow model.

According to equation (1), the FCF is defined as the difference between revenues and the sum of capital expenditures (CAPEX), operation expenditures (OPEX), decommissioning expenditures, and tax payments. Equation (2) describes the structure of the entire project life cycle, which can be roughly divided into the planning and construction, operation and decommissioning. The calculation of CAPEX is performed via equation (3) and the determination of revenues is made by means of equation (4). The latter includes the multiplication of the feed-in tariff and the electricity yield. This, in turn, is calculated by the integration of a Weibull wind speed distribution and the turbines' cumulative power curve multiplied by the theoretical operating hours per period (here: 8,760 $\mathrm{h} /$ year) and different losses parameters. Equation (5) determines the OPEX. Decommissioning expenditures at the end of the project are calculated via equation (6) 


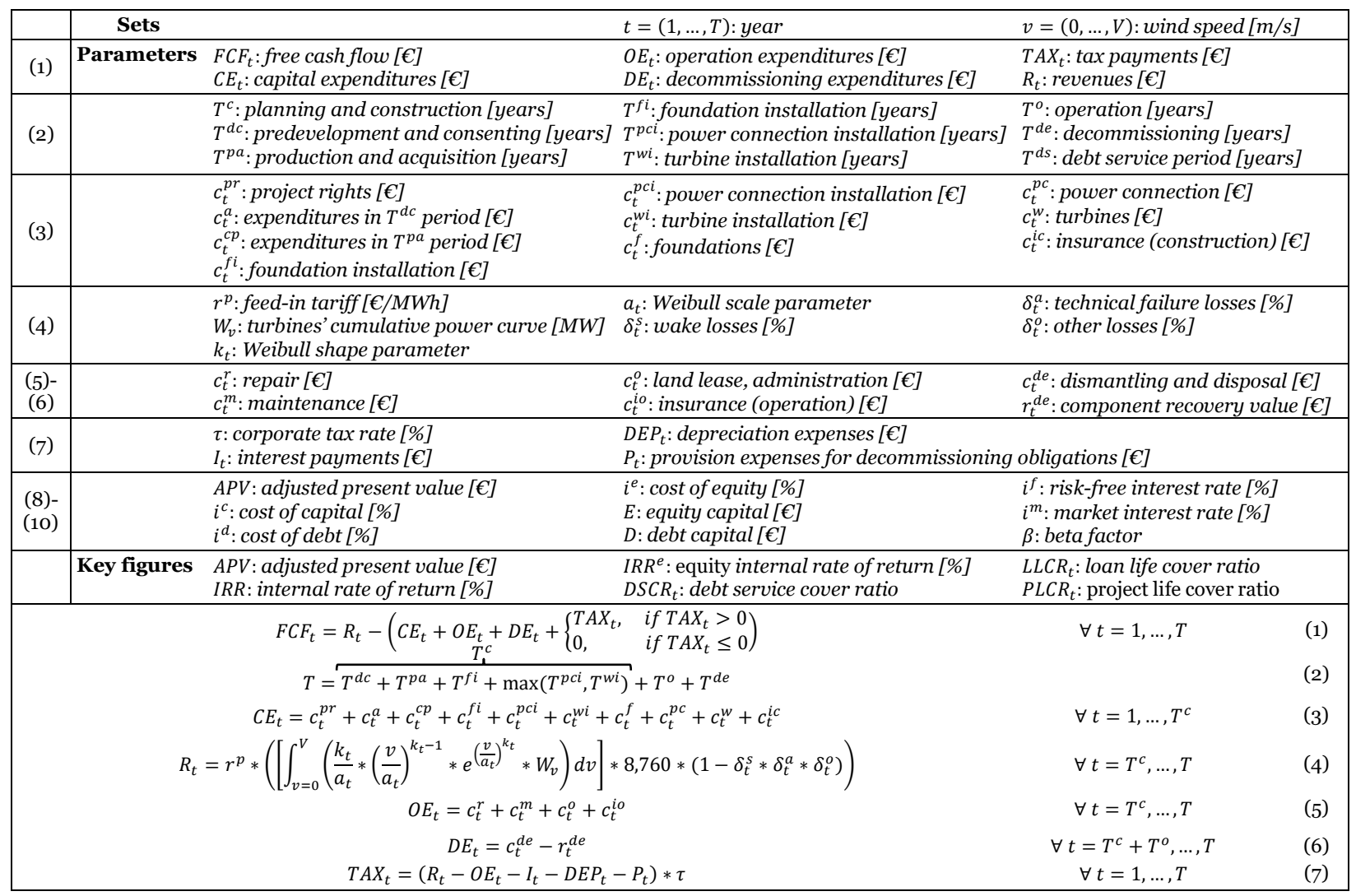

Figure 2: Sets, parameters, and equations of the cash flow model

and represent the difference between the dismantling and disposal expenditures and the components' recovery values. Equation (7) calculates the tax payments. Beside revenues and OPEX, the former requires information about the interest payments, depreciation expenses, and provision expenses for decommissioning obligations.

The weighted average cost of capital (WACC) and the adjusted present value (APV) method are applied in related research $[19,20]$ to discount the FCF at the valuation date. The two approaches differ with regard to the consideration of tax advantages that arise from interest payments due to external financing [26]. Most OWE projects are financed via special purpose vehicles which are characterized by debt-to-equity ratios that are strongly inconstant during the project life cycle. Thus, we use the APV method since it is a better choice when these conditions apply [27].

The APV is calculated according to equation (8) by adding the discounted FCFs and tax shields among the project life cycle. While the FCFs are discounted by the cost of capital, the tax shields are discounted by the cost of debt. The cost of capital is expressed by equation (9) and represents the average of the costs of equity and debt, weighted with the shares of equity and debt. As shown in formula (10), the cost of equity is determined according to the capital asset pricing model (CAPM). With the CAPM, an appropriate required rate of return can be specified by estimating the expected return of an alternative investment into a diversified and risk-adjusted market portfolio [28].

$$
\begin{gathered}
A P V=\sum_{t=1}^{T} \frac{F C F_{t}}{\left(1+i^{c}\right)^{t}}+\frac{\tau * I_{t}}{\left(1+i^{d}\right)^{t}} \\
i^{c}=i^{e} * \frac{E}{E+D}+i^{d} * \frac{D}{E+D} \\
i^{e}=i^{f}+\left(i^{m}-i^{f}\right) * \beta
\end{gathered}
$$

\subsection{Financial Key figures}

To allow further financial analyses, we provide additional key figures important for lenders and equity investors. Lenders need key figures that evaluate the debt service coverage. The debt service cover ratio (DSCR) measures the debt service coverage for every single period of a project. It is the quotient of the cash flow available for debt service (CFADS) and the debt service [29], see equation 11.

$D S C R_{t}=\frac{R_{t}-\left(O E_{t}+T A X_{t}\right)}{D S_{t}} \quad \forall t=T^{c}+1, \ldots, T^{d s}$ 
Other key figures that provide further information about the ability of debt repayments are the loan life cover ratio (LLCR) and the project life cover ratio (PLCR). They are only useful in combination with the DSCR. The IRR represents the discount factor that results in a project value of zero and thus indicates the interest yield an investor can reach with an investment.

\subsection{Risk model, correlations and MCS}

A pure contemplation of the expected values does not provide a sufficient basis for a comprehensive financial analysis and related investment decisions due to an inadequate consideration of project risks [19]. Investments must always be assessed against the background of the investor's individual risk aversion and risk-bearing capacity. We developed a risk model which considers a total of five risk factors and lead to 27 probabilistic parameters in the DCF model. As certain parameters are interrelated [17], the risk model also takes correlations into account. This is realized by the implementation of the Iman-Conover method. Rank order correlation can be induced between randomly distributed variables irrespective of their distributions and without changing their shape [30].

On top of the DCF model, we apply an MCS which is a method that belongs to the stochastic theory and is commonly used in analyses of investment projects subject to risk [31]. The MCS results in multiple vectors or distributions that represent approximations of parameters and key figures. Based on the key figure distributions, value-at-risk ( $\mathrm{VaR})$ analyses can be performed. The VAR specifies the maximum monetary loss that is not exceeded within a fixed period of time and an explicit confidence level. When applied to the APV, the VAR expresses the minimum project value that is not undershot by a certain probability (confidence level). The VAR can analogously be applied to the other key figures of our cash flow model.

\subsection{Decision support system: INRIAN-WE}

Our INRIAN-WE DSS is a MATLAB-based desktop application that is provided as a multi-platform executable. It is compatible with the operating systems Windows, Mac OS X, and Linux. The DSS integrates the DCF model, the control of an MCS, visualization of results as well as input and output functionality to easily provide decision support. The architecture of the system and the data flow is illustrated in Figure 3. Users initially need to specify a dataset that represents the case study and serves as the external input necessary for the MCS. All parameters of an OWP can be im- and exported from .mat files by using the GUI.

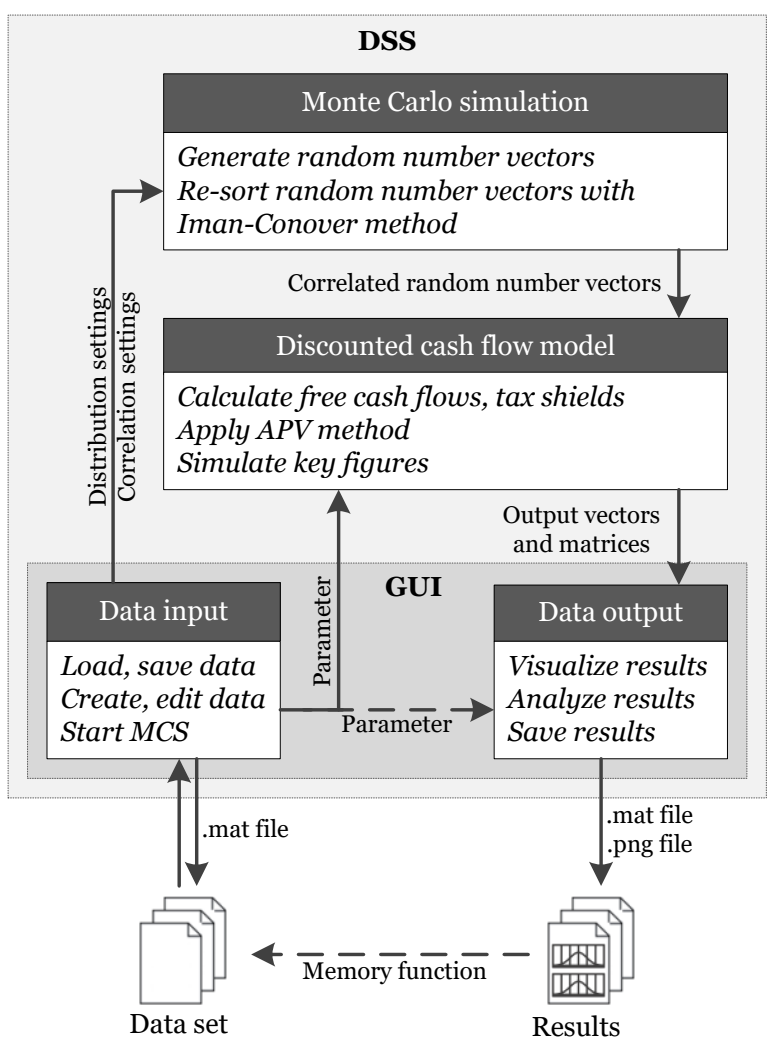

Figure 3: System architecture of the DSS

\section{Case study: OWE in Mexico}

To demonstrate the applicability of our research artifacts, INRIAN-WE is used to assess fictional OWE projects located at five different areas in Mexico. The locations and their corresponding average wind speed as well as parameters for the respective Weibull distributions which characterize the distributions of wind speeds are presented in Table 1. The examined projects are fictitious but based on data of real projects in Oaxaca. The projects consist of 41 turbines from Gamesa which is the main wind turbine supplier in Mexico [32]. Each turbine has 2.5 MW nominal power output. Planning and construction periods are set to 2 years in total. The installation of turbines and power connection is performed simultaneously. The total project lifetime is 20 years.

\section{Table 1: Assumptions of Mexican projects}

\begin{tabular}{|l|c|c|c|}
\hline Location & $\begin{array}{c}\text { Average wind } \\
\text { speed [m/s] }\end{array}$ & $\begin{array}{c}\text { Scale } \\
\text { factor k }\end{array}$ & $\begin{array}{c}\text { Shape } \\
\text { factor c }\end{array}$ \\
\hline La Venta, Oaxaca & 12.54 & 1.906 & 13.573 \\
La Laguna, BCS & 8.65 & 2.394 & 9.193 \\
San Quintin, BCN & 7.43 & 2.578 & 7.803 \\
Telchac Puerto, Yucatan & 7.25 & 2.739 & 7.581 \\
Matamoros, Tamaulipas & 6.67 & 1.883 & 6.925 \\
\hline
\end{tabular}


Table 2: Assumptions of Mexican wind farms with $30 \%$ equity (currency in MXN)

\begin{tabular}{|c|c|c|c|c|c|}
\hline Parameter & Value & Disc./prem. & Parameter & Value & Disc./prem. \\
\hline Turbine type & \multicolumn{2}{|c|}{ Gamesa-G114-2.5MW } & Equity capital $[\$ \mathrm{M}]$ & 1162 & - \\
\hline Turbine amount & 41 & - & Annuity loan I volume [\$M] & 1627 & - \\
\hline Expected annual electricity out. & 565 & - & Annuity loan I interest [\%/year] & $8.9 \%$ & $-10 \% /+10 \%$ \\
\hline Project start [year] & 2017 & - & Annuity loan I debt service period & 14 & \\
\hline Predevelopment and consenting [years] & 0.5 & $-25 \% /+25 \%$ & Annuity loan II volume [€M] & 1085 & - \\
\hline Production and acquisition [years] & 0.5 & $-25 \% /+25 \%$ & Annuity loan II interest [\%/year] & $7.2 \%$ & $-10 \% /+10 \%$ \\
\hline Foundation installation [years] & 0.4 & $-25 \% /+50 \%$ & Annuity loan II debt service period & 14 & - \\
\hline Power connection installation [years] & 0.5 & $-25 \% /+50 \%$ & Risk-free interest rate [\%] & 0.8 & - \\
\hline Turbine installation [years] & 0.6 & $-25 \% /+50 \%$ & Market interest rate [\%] & 7.4 & - \\
\hline Operation [years] & 20 & - & Beta factor & 1.27 & - \\
\hline Decommissioning [years] & 0.5 & $-25 \% /+50 \%$ & Dismantling and disposal [\$M] & 390 & $-25 \% /+75 \%$ \\
\hline Project rights $[\$ \mathrm{M}]$ & 204 & $-5 \% /+5 \%$ & Component recovery value [\$M] & 80 & $-25 \% /+25 \%$ \\
\hline Predevelopment \& consenting [\$ M] & 81 & $-10 \% /+10 \%$ & Repair [\$M/year] & 43.7 & $-25 \% /+25 \%$ \\
\hline Production and acquisition [\$M] & 102 & $-10 \% /+10 \%$ & Maintenance [\$M/year] & 21.5 & $-5 \% /+5 \%$ \\
\hline Foundations $[\$ \mathrm{M}]$ & 717 & $-10 \% /+10 \%$ & Land lease, administration [\$M/year] & 10.2 & $-5 \% /+5 \%$ \\
\hline - Installation [\$M] & 155 & $-5 \% /+20 \%$ & Insurance (operation) [\$M/year] & 26.5 & - \\
\hline Power connection $[\$ \mathrm{M}]$ & 310 & $-10 \% /+15 \%$ & Corporate tax rate $[\%]$ & 30 & - \\
\hline - Installation [\$M] & 93 & $-5 \% /+20 \%$ & Wake losses [\%] & 5 & $-20 \% /+20 \%$ \\
\hline Turbines $[\$ \mathrm{M}]$ & 2150 & $-5 \% /+5 \%$ & Technical failure losses [\%] & 3,5 & $-50 \% /+50 \%$ \\
\hline - Installation [\$M] & 62 & $-5 \% /+20 \%$ & Other losses [\%] & 3.5 & $-50 \% /+50 \%$ \\
\hline
\end{tabular}

Table 2 illustrates the dataset that serves as a basis for the assessments of all projects at the different locations. In the literature, the investment costs for OWE projects in Mexico are calculated on a basis of 37.8 million MXN/MW installed capacity under consideration of an annual inflation rate and a currency exchange rate of $21.16 \mathrm{MXN} / \mathrm{EUR}[8,9]$. They are divided into multiple cost components. The breakdown of the total costs to individual components is based on analyses of the recent past $[8,9]$. According to the studies, the annual operating costs amount to 101.9 million MXN in the first year of operation which is the result of the installed capacity of $102.5 \mathrm{MW}$ multiplied by the specific annual operating costs of 0.9941 million MXN/MW. They are split up into four components, based on [9]. Decommissioning costs at the end of the project life cycle are set to 310 million MXN. These consists of dismantling and disposal costs 390 million MXN reduced by the component recovery value of 80 million MXN.

The electricity prices in Mexico are appointed in power purchase agreements (PPA). For the analysis of projects at the different locations, we consistently make use of the PPA of the realized project Piedra Larga which specifies 1,120 MXN/MWh. When installed in La Venta, Oaxaca, the wind turbines would generate an expected annual electricity output of 565 GWh. At this location, the expected annual revenues are approximately $565 \mathrm{GWh} \times 1,120 \mathrm{MXN} / \mathrm{MWh}=$ 632.8 million MXN. Due to less favorable wind conditions, lower annual electricity outputs and thus, lower revenues are expected for the other locations. Profits are subject to a corporate tax rate of $30 \%$.

\subsection{Discount rate and probability distributions}

To apply the APV method, discount rates have to be determined. The return on equity (equation 10) is calculated with a risk-free interest rate of $0.8 \%$, which refers to long term bonds from Germany, a market risk premium of $7.4 \%$ [33], and a beta of 1.27 . The beta factor is derived from the average unlevered beta of 1.07 for companies that operate in the Mexican onshore wind market. The return on equity results in $0.8 \%+(7.4 \%-0.8 \%) \times 1.27=9.18 \%$. Next, the cost of debt is determined. The Inter-American Development Bank or the World Bank supported Mexican OWE projects in the past. We assume participation on the debt of $40 \%$ at $7.2 \%$. Other banks provide $60 \%$ of the debt at $8.9 \%$ interest rate which leads to a weighted cost of debt of $8.22 \%$. Finally, the discount rate is calculated (equation 2) with a share of debt of $70 \%: 9.18 \% \times 30 \%+8.22 \% \times 70 \%=8.51 \%$.

To perform an MCS with BetaPERT probability distributions, it is necessary to specify a minimum, a maximum, and a most likely value for every risky parameter. While all expected values of these parameters are used as most likely values, the minimum and maximum points are calculated by discounts from and surcharges on top of the expected values.

\subsection{Project assessments}

All previously mentioned parameters and values are inserted into the discounted cash flow model. The MCS is performed with 20,000 iterations for each location using MATLAB R2016a on an Intel® Core $^{\mathrm{TM}}$ 
i7-4710MQ CPU with 2.5 GHz, $20 \mathrm{~GB}$ RAM and Microsoft Windows 7 64-bit as the operating system. The simulation for each location requires 43 minutes. The results of the simulation are presented for the $90 \%$ confidence levels of all key figures at different equity shares in Table 3 . We choose this confidence level to ensure sufficient certainty regarding the required values of examined key figures. The results allow different statements about the analyzed OWE projects:

1. Only the project in La Venta, Oaxaca provides very positive returns for investors and sufficient debt service coverage regardless of the equity share.

2. Revenues from selling the produced electricity are too low in all other regions to meet requirements of investors and lenders. Thus, higher compensations are required to support an expansion of wind energy in other Mexican regions.

3. The project in La Laguna, BCS shows that an OWE project which is attractive in economic terms is not necessarily financeable (positive APV but DSCR lower than 1 at $30 \%$ equity) and vice versa (negative APV but DSCR of 1 at $40 \%$ equity).

\subsection{Support scheme concept}

Based on the demonstrated results, we adapt a concept of a uniform support scheme from Germany which offers transparent conditions that fits for projects all over a country and does not require project specific negotiations. The support scheme is realized with a site quality adjustment factor that considers certain conditions of any location compared to a $100 \%$ reference site [34]. In our case of Mexico, we will in favor of an easy application and comparison of different locations refer to the average wind speed.

As the project in La Laguna, BCS is almost financeable and profitable with a $35 \%$ equity share (see Table 3), we increase the compensation for the produced electricity of this project in iterative steps to identify the minimum required compensation that fulfills the needs of investors as well as lenders at a 90\% confidence level. Figure 4 shows that a minimum DSCR of 1 and an APV greater than 0 is achieved for this confidence level when the compensation is set to 1,225 MXN/MWh. Although this result does not apply for other equity shares, we define the site conditions of La Laguna, BCS with an average wind speed of 8.65 $\mathrm{m} / \mathrm{s}$ as the $100 \%$ reference site.

Next, we identify minimum electricity compensations for projects with other site qualities which barely make them financeable as well as profitable. Thus, we increase or decrease the compensations of the other four projects as well as additional fictitious projects at different locations with various average wind speeds. The final step is a normalization of the identified minimum compensations. All identified compensations are divided by 1,225 $\mathrm{MXN} / \mathrm{MWh}$ which is the identified compensation of our $100 \%$ reference site at La Laguna, BCS to calculate adjustment factors. The result is a list of projects with their average wind speed, corresponding site quality factor, minimum required compensation and calculated adjustment factor. Major parts of the result list are

Table 3: Financial key figures of all projects at $90 \%$ confidence levels

\begin{tabular}{|l|r|c|r|c|r|r|}
\cline { 2 - 7 } \multicolumn{1}{c|}{} & \multicolumn{2}{c|}{$30 \%$ equity } & \multicolumn{2}{c|}{ 35\% equity } & \multicolumn{2}{c|}{ 40\% equity } \\
\hline Location & \multicolumn{1}{c|}{ APV } & Min DSCR & APV & Min DSCR & \multicolumn{1}{c|}{ APV } & Min DSCR \\
\hline La Venta, Oaxaca & $814.7 \mathrm{M} \$$ & 1.07 & $744.0 \mathrm{M} \$$ & 1.15 & $665.4 \mathrm{M} \$$ & 1.25 \\
La Laguna, BCS & $10.4 \mathrm{M} \$$ & 0.86 & $-31.2 \mathrm{M} \$$ & 0.92 & $-77.8 \mathrm{M} \$$ & 1.00 \\
San Quintin, BCN & $-794.2 \mathrm{M} \$$ & 0.65 & $-832.0 \mathrm{M} \$$ & 0.70 & $-687.9 \mathrm{M} \$$ & 0.76 \\
Telchac Puerto, Yucatan & $-931.9 \mathrm{M} \$$ & 0.61 & $-964.3 \mathrm{M} \$$ & 0.66 & $-1013.9 \mathrm{M} \$$ & 0.71 \\
Matamoros, Tamaulipas & $-1390.3 \mathrm{M} \$$ & 0.45 & $-1436.9 \mathrm{M} \$$ & 0.49 & $-1466.8 \mathrm{M} \$$ & 0.53 \\
\hline
\end{tabular}
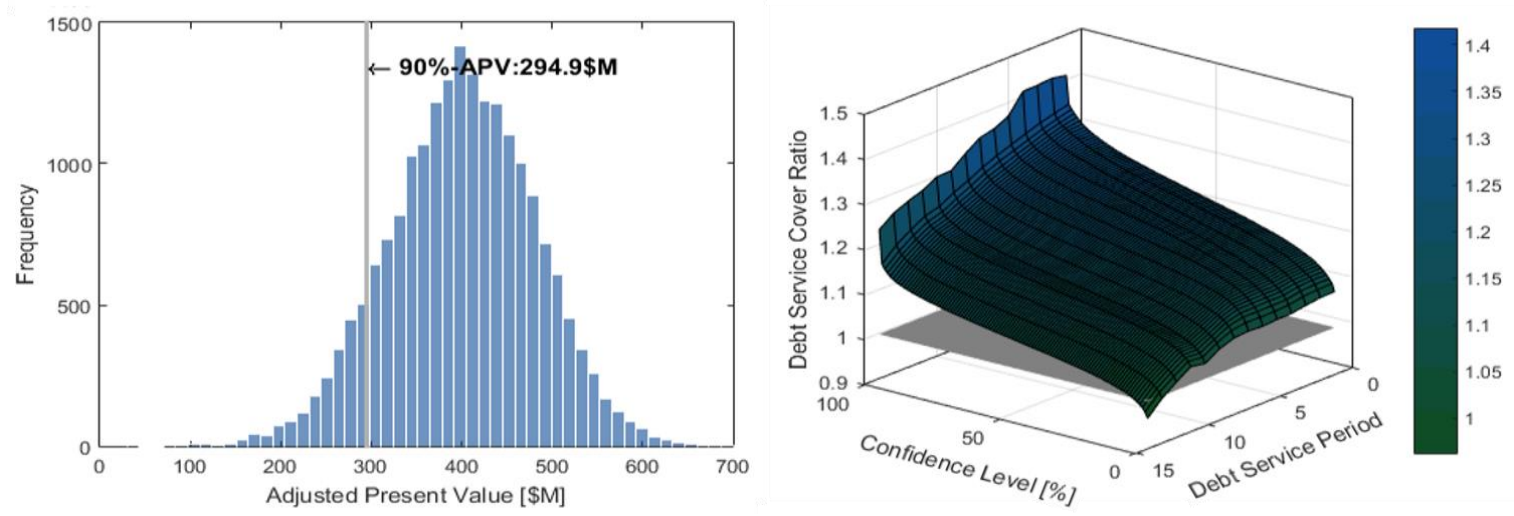

Figure 4: APV and DSCR - La Laguna, BCS - 35\% equity, 1,225 MXN/MWh 


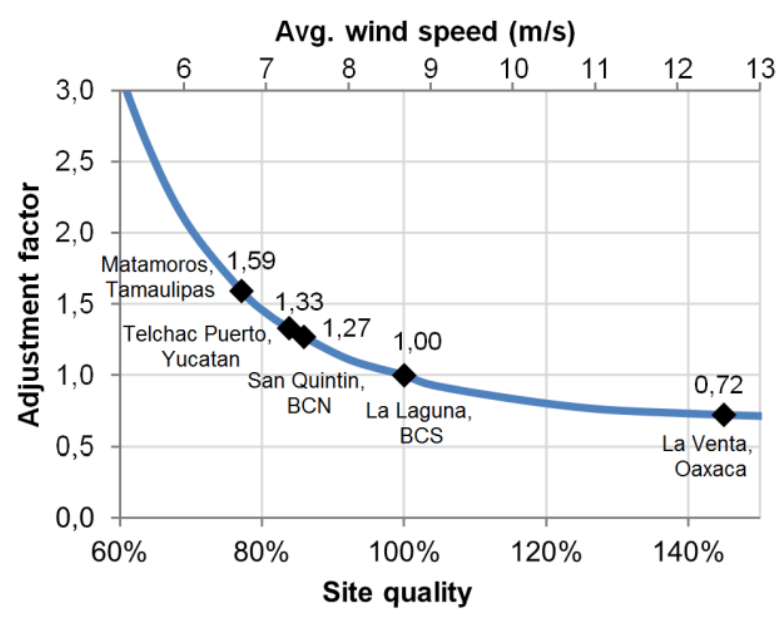

Figure 5: Site quality adjustment curve

presented in Figure 5. By connecting the data points of the adjustment factors for all site qualities we achieve the site quality adjustment curve (SQAC). The presented results show that the required compensation for electricity is not linearly depending on the average wind speed. Instead, the adjustment factor increases exponentially with decreasing site qualities. These findings are similar to the SQAC implemented in the German OWE support scheme [34].

\section{Discussion and limitations}

We constructed and evaluated research artifacts that assess the economic feasibility of OWE projects in Mexico under the prevailing general conditions in order to provide decision support. A DCF model based on established discounting methods was formulated to fit this task. To further provide decision support, we implemented the INRIAN-WE DSS that integrates the model and additional components in an intuitive IS. Due to the fact that both wind energy and renewable energies in general as well as our system aim at ecological and economic sustainability, we claim that the system is both a Green IS and a Green DSS.

The presented results for projects all over Mexico clearly indicate that the attractiveness of investments into OWE projects in Mexico highly depends on the compensations for the produced electricity. Our approach of a SQAC is a transparent and uniform method that enables users to compare projects based on their site quality. This could serve as a basis for the implementation of a fixed feed-in-tariff that links the specific compensation of a project to its site quality.

In case a more competitive approach is wanted, the SQAC can also be used within a national auction system that simultaneously focusses on a national expansion of OWE and a subsidy reduction on the governmental side. Bids of auction participants could be adjusted by the adjustment factor corresponding to their project's site quality when determining the most competitive projects. Against the background of extremely good wind conditions in Oaxaca compared to all other Mexican regions, such a system avoids an OWE expansion only in this area. This promotes the reliability of the electricity grid's availability and stability and reduces the need for grid expansions since electricity can be consumed where it is generated due to a decentralized integration of wind energy into the existing system. However, regions with a site quality factor lower than $80 \%$ could be excluded because of too high subsidy requirements and the availability of several better sites across Mexico [10,11,12].

With this example we show that the DSS is able to support governments in checking whether the respective general financial conditions are sufficient to support the expansion of OWE. It can also assist investors and lenders with the complex tasks of assessing possible project returns and the project's ability to cover debt service.

The subsequent discussion follows remarks of Arnott and Pervan [35] about design science in DSS research. They state that a key differentiator between design science and routine design practice is the amount of innovation or novelty of the artifacts and that DSR should address important topics and produce contributions to both IS theory and practice. Our research contributions belong to design science as we follow a rigorous research process and our artifacts address important topics of OWE and Green IS.

Following the argumentation of [35] that the abstract artifacts (constructs, models, and methods) contribute to theory, our DCF model, in combination with the applied MCS, also contributes to this subject. The latter points out effects of critical project risks on different financial key figures. There are only few findings in the literature about these effects on the indicators that are particularly important for the lenders. This indicates that the consideration of risk factors for the assessment of relevant key figures for wind projects has not yet been sufficiently researched.

Our INRIAN-WE DSS as an instantiation also has a practical focus and is utilized to demonstrate the use of the artifact to solve a problem [22]. Our DSS helps to check the applicability of the underlying model and the applied method. It can support decision makers in assessing the economic potential of OWE projects. Investors demand information about the interest rate that can be achieved. Thus, the calculation of the project value and the subsequent computation of the IRR are of high practical relevance. Lenders focus on the project's ability to cover debt service. The calculation of key figures like the DSCR addresses 
their requirements. Politicians want to support an expansion of renewable energies but limit subsidies. Assessments of projects under consideration of site specific conditions assist setting up a support scheme that exactly fit to national requirements.

INRIAN-WE helps users understand the effects of changes in the general conditions like the support scheme, a changed cost situation of individual cost factors, or alternative discount factors. The influence of risks on a project's success becomes clear. Against this background, the importance of risk management is emphasized. The examination of critical risk factors offers a possibility to detect which risks are the greatest threats to the success of a project and at which point of time in the planning or operating process it is most important to establish risk management methods.

We identified certain limitations with regard to our research artifacts. Our research artifacts are evaluated for Mexican OWE projects for which only rough data is available. The DCF model, the subsequently applied MCS, and the DSS should be evaluated for other regions. DSR aims at adopting artifacts by practitioners, but yet only $13.5 \%$ of DSS designscience research artifacts are evaluated in the field [35]. An empirical evaluation in the field by project developers and lenders can help to increase rigor and the generalizability for our approach. The DCF model uses a single corporate tax rate. When it comes to more complex tax systems, our model provides only an approximation. Deviations of the real situation depend strongly on the individual case. However, the key findings of the model retain their validity.

The results of the MCS are based on correlated BetaPERT probability distributions. The shape of the BetaPERT distribution itself provides only a rough approximation of actually occurring risks. A better consideration of critical risk factors can be realized by an expansion of respective knowledge when more and longer experiences and better scientific investigations of planning, construction, and operation of onshore wind farms are made. In this case, the BetaPERT distributions can be replaced by more realistic ones. However, no major improvements of the data situation can be expected because the companies involved classify the majority of this data as secret information.

Several theoretical and practical implications can be outlined from this paper. With regard to theoretical implications, a model to assess wind energy projects in emerging countries exists now. The DCF model can be used as foundation for other research that deals with projects in other areas or countries. Researchers can use the model from the academic knowledge base, adapt it, and apply it to a specific task. With regard to economic and ecological sustainability, researchers as well as experts and politicians in or responsible for the wind energy sector can use our quantitative approach as a starting point to further evaluate and increase the profitability or sustainability of certain OWE projects or the whole energy sector within a country.

From an academic point of view, we claim that Green DSS is an important subfield of Green IS, and we provide an example of an actual Green DSS. Both our model and DSS aim to increase the environmental and economic sustainability of energy production. Our DSS enables quick decision making. To address changing variability, stakeholders can use our system to run through different scenarios by setting parameters, e.g. discount factors or probability distributions. The integrated DSS enables decision support by creating visual representation of the results.

\section{Conclusion and outlook}

Important issues concerning renewable energies, including the expansion of wind energy and Green IS require further research. In this paper, an DSS is presented that helps to assess wind energy projects and allows users to evaluate whether sufficient financial support is provided by a government to promote the expansion of the wind sector. Within the designoriented research, a DCF model was formulated to calculate important key figures like the project value, and DSCR to consider the requirements of all stakeholders. This model is employed by our INRIANWE DSS, which allows for structured capturing of relevant data and determining probability distributions to consider project risks. It also triggers the MCS and the visualization of results.

The applicability of the DSS and the underlying model is evaluated in a case study of the Mexican wind energy sector. The results show that the absence of support schemes has led to PPAs that overcompensate investors. We address this issue by presenting a concept for the design of a uniform support scheme that focusses on adequate compensation of investors and sufficient debt service coverage and promotes widespread expansion of wind energy in different Mexican regions. Our concept can be the basis for the implementation of either fixed-feed-in tariffs or a more competitive auction-based system.

Further research steps regarding our artifacts and the identified limitations are required. Issues of the design of IS that facilitate the implementation of our proposed support scheme should be addressed. Further, a deeper analysis and validation of the artifacts that go beyond the application example is needed. A database with reliable and more accurate information on the costs and performance as well as special risks of certain wind projects in Mexico could lead to a more robust foundation for the design of a support scheme. 


\section{References}

[1] C. Wolfram, O. Shelef, and P.J. Gertler, "How will energy demand develop in the developing world?", National Bureau of Economic Research, 2012.

[2] S. Chu, and A. Majumdar, "Opportunities and challenges for a sustainable energy future", Nature, 488, 2012, pp. 294-303.

[3] Y. Cancino-Solórzano, A. J. Gutiérrez-Trashorras, J. Xiberta-Bernat, "Current state of wind energy in Mexico, achievements and perspectives", Renewable and Sustainable Energy Reviews 15(8), 2011.

[4] Global Wind Energy Council (GWEC), "Global Wind Report - Annual Market Update 2015”, 2016.

[5] J. Dedrick, "Green IS: concepts and issues for information systems research", Communications of the Association for Information Systems, 27(1), 2010.

[6] R.T. Watson, M.C. Boudreau, and A.J. Chen, "Information systems and environmentally sustainable development: energy informatics and new directions for the IS community", MISQ, 34(1), 2010, pp. 23-38.

[7] J.V. Brocke, R.T. Watson, C. Dwyer, S. Elliot, and N. Melville, "Green Information Systems: Directives for the IS Discipline", ICIS 2012 Proceedings, 2012.

[8] International Energy Agency (IEA) Wind, "Annual Report 2012", 2013.

[9] International Renewable Energy Agency (IRENA), "Renewable Power Generation Costs in 2014", 2015.

[10] O.A. Jaramillo, M.A. Borja, "Wind speed analysis in La Ventosa, Mexico: a bimodal probability distribution case", Renewable Energy 29(10), 2004, pp.1613-1630.

[11] O.A. Jaramillo, R. Saldaña, U. Miranda, "Wind power potential of Baja California Sur, México", Renewable Energy 29(13), 2004, pp. 2087-2100.

[12] Q. Hernández-Escobedo, F. Manzano-Agugliaro, A. Zapata-Sierra, "The wind power of Mexico", Renewable and Sustainable Energy Reviews, 14(9), 2010, pp. 2830-2840.

[13] M.I. Blanco, "The economics of wind energy", Renewable and Sustainable Energy Reviews, 13(6-7), 2009, pp. 1372-1382.

[14] S. de Oliveira, A.J. Fernandes, "Economic feasibility applied to wind energy projects", International Journal of Emerging Sciences, 1(4), 2011, pp. 659-682.

[15] I. Peña, I. L. Azevedo, L.A.F.M. Ferreira, "Economic analysis of the profitability of existing wind parks in Portugal”, Energy Economics, 45, 2014, pp. 353-363.

[16] A. Colmenar-Santos, S. Campíñez-Romero, C. PérezMolina, F. Mur-Pérez, "Repowering: An actual possibility for wind energy in Spain in a new scenario without feed-in-tariffs", Renewable and Sustainable Energy Reviews, 41, 2015, pp. 319-337.

[17] L. Kitzing, C. Weber, "Support mechanisms for renewables: how risk exposure influences investment incentives", International Journal of Sustainable Energy Planning \& Management, 7, 2015, pp.117-134.

[18] I. Khindanova, "A Monte Carlo Model of a Wind Power Generation Investment", The Journal of Applied Business and Economics, 15(1), 2013, pp. 94-106.
[19] A. Koukal, M. H. Breitner, "Offshore wind energy in emerging countries: a decision support system for the assessment of projects", HICSS 2014 Proceedings, 2014, pp. 865-874.

[20] R. Madlener, L. Siegers, and S. Bendig, "Risk Management of Offshore Wind Energy Plants", "Risikomanagement und -controlling bei OffshoreWindenergieanlagen" (in German), Zeitschrift für Energiewirtschaft, 33, 2009, pp. 135-146.

[21] P. Offermann, O. Levina, M. Schönherr, and U. Bub, "Outline of a Design Science Research Process", Proceedings of the 4th International Conference on Design Science Research in Information Systems and Technologies, Philadelphia, 2009.

[22] K. Peffers, T. Tuunanen, M.A. Rothenberger, and S. Chatterjee. "A design science research methodology for information systems research", Journal of Management Information Systems, 24(3), 2008, pp. 45-77.

[23] A.R. Hevner, S.T. March, J. Park, and S. Ram, "Design Science in Information Systems Research", MISQ, 28(1), 2004, pp. 75-105.

[24] A.R. Hevner, "A Three Cycle View of Design Science Research", Scandinavian Journal of Information Systems, 19(2), 2007.

[25] P. Palvia, V. Midha, and P. Pinjani, "Research Models in Information Systems", Communications of the Association for IS, 17(1), 2006, pp. 1042-1066.

[26] P. Fernandez, "The value of tax shields is NOT equal to the present value of tax shields", Journal of Financial Economics, 73, 2004, pp. 145-165.

[27] R. Luehrman, "Using APV: A better tool for valuing operations", Harvard Business Review, 75, 1997, pp. $145-154$

[28] Da, Z., R-J. Guo and R. Jagannathan, "CAPM for estimating the cost of equity capital: interpreting the empirical evidence", Journal of Financial Economics, 103(1), 2012, pp. 204-220.

[29] F. Pretorius, B.F. Chung-Hsu, A. McInnes, P. Lejot, D. Arner, "Finance for Construction and Infrastructure: Principles and Case Studies", Wiley, 2008.

[30] R. L. Imam, W. Conover, "A distribution-free approach to inducing rank correlation among input variables", Communications in Statistics-Simulation and Computation, 11(3), 1982, pp. 311-334.

[31] V. Platon, A. Constantinescu, "Monte Carlo method in risk analysis for investment projects", Procedia Economics and Finance, 15, 2014, pp. 393-400.

[32] Mexican Wind Power Association (AMDEE), "Wind Farms in México 2015", http://www.amdee.org/windfarms-mexico-2015, 2016.

[33] P. Fernandez, J. Aguirreamalloa, and L.C. Avendaño, "Market risk premium used in 88 Countries in 2014: a survey with 8,228 answers", IESE Business School, University of Navarra, Madrid, Spain, 2013.

[34] German Federal Ministry for Economic Affairs and Energy, "2016 Revision of the Renewable Energy Sources Act - Key points (revised)", 2016.

[35] D. Arnott, and G. Pervan, "Design Science in Decision Support Systems Research: An Assessment using the Hevner, March, Park, and Ram Guidelines", Journal of the Association for IS, 13(11), 2012, pp. 923-949. 